Article

\title{
Synthesis of Au-Ag Alloy Nanoparticle-Incorporated AgBr Crystals
}

\author{
Shin-ichi Naya ${ }^{1}$, Musashi Fujishima ${ }^{2}$ and Hiroaki Tada ${ }^{1,2, *(\mathbb{D}}$ \\ 1 Environmental Research Laboratory, Kindai University, 3-4-1, Kowakae, Higashi-Osaka, \\ Osaka 577-8502, Japan \\ 2 Graduate School of Science and Engineering, Kindai University, 3-4-1, Kowakae, Higashi-Osaka, \\ Osaka 577-8502, Japan \\ * Correspondence: h-tada@apch.kindai.ac.jp; Tel.: +81-6-6721-2332; Fax: +81-6-6727-2024
}

Received: 1 August 2019; Accepted: 30 August 2019; Published: 3 September 2019

\begin{abstract}
Nanoscale composites consisting of silver and silver halide ( $\mathrm{Ag}-\mathrm{AgX}, \mathrm{X}=\mathrm{Cl}, \mathrm{Br}, \mathrm{I})$ have attracted much attention as a novel type of visible-light photocatalyst (the so-called plasmonic photocatalysts), for solar-to-chemical transformations. Support-free $\mathrm{Au}-\mathrm{Ag}$ alloy nanoparticle-incorporated $\mathrm{AgBr}$ crystals (Au-Ag@AgBr) were synthesized by a photochemical method. At the initial step, Au ion-doped AgBr particles were prepared by adding an aqueous solution of $\mathrm{AgNO}_{3}$ to a mixed aqueous solution of $\mathrm{KBr}$ and $\mathrm{HAuBr}_{4}$. At the next step, UV-light illumination $(\lambda=365 \mathrm{~nm})$ of a methanol suspension of the resulting solids yielded $\mathrm{Au}-\mathrm{Ag}$ alloy nanoparticles with a mean size of approximately $5 \mathrm{~nm}$ in the micrometer-sized $\mathrm{AgBr}$ crystals. The mole percent of $\mathrm{Au}$ to all the $\mathrm{Ag}$ in $\mathrm{Au}-\mathrm{Ag} @ \mathrm{AgBr}$ was controlled below $<0.16 \mathrm{~mol} \%$ by the $\mathrm{HAuBr}_{4}$ concentration in the first step. Finite-difference time-domain calculations indicated that the local electric field enhancement factor for the alloy nanoparticle drastically decreases with an increase in the Au content. Also, the peak of the localized surface plasmon resonance shifts towards longer wavelengths with increasing $\mathrm{Au}$ content. $\mathrm{Au}-\mathrm{Ag} @ \mathrm{AgBr}$ is a highly promising plasmonic photocatalyst for sunlight-driven chemical transformations due to the compatibility of the high local electric field enhancement and sunlight harvesting efficiency.
\end{abstract}

Keywords: silver halide; silver-gold alloy nanoparticle; local electric field enhancement; plasmonic photocatalyst

\section{Introduction}

In view of energy and environmental issues, solar energy utilization for the production of useful chemicals and for the decomposition of harmful environmental pollutants has become increasingly important. Nanoparticles (NPs) made from Ag and Au have high absorption due to the localized surface plasmon resonance (LSPR). The LSPR excitation-driven photocatalysts represented by $\mathrm{Au}$ $\mathrm{NP}-$ loaded $\mathrm{TiO}_{2}\left(\mathrm{Au} / \mathrm{TiO}_{2}\right)$ have emerged as a new type of visible-light photocatalysts [1,2]. Among the plasmonic photocatalysts, silver-silver halides $(\mathrm{Ag}-\mathrm{AgX}, \mathrm{X}=\mathrm{Cl}, \mathrm{Br}, \mathrm{I})$ also exhibit visible-light activity for important chemical reactions including hydrogen evolution [3,4] and $\mathrm{CO}_{2}$ reduction [5-7]. Recently, Ag NP-incorporated $\mathrm{AgBr}$ crystals on $\mathrm{TiO}_{2}$ have been shown to work as a plasmonic photocatalyst via the local electric field enhancement (LEFE) mechanism [8]. In this case, the key to improving the solar-to-chemical conversion efficiency is the compatibility of high LEFE and sunlight harvesting efficiency (LHE) [9]. Figure 1a shows the absorption spectra of spherical Au-Ag alloy NPs in water calculated as a function of the Au mole fraction $(x)$ by the finite-difference time-domain (FDTD) method. Most LSPR absorption of Ag NPs is located at a wavelength region below $400 \mathrm{~nm}$, while the absorption spectrum for $\mathrm{Au}$ NPs matches well with the solar spectrum. In the $\mathrm{Au}_{x}-\mathrm{Ag}_{1-x}$ alloy system, the LSPR peak redshifts from $390 \mathrm{~nm}$ at $x=0$ to $530 \mathrm{~nm}$ at $x=1$. The light absorption or the generation rate of 
the photocharge carriers is proportional to the electric field squared $|E|^{2}[10]$. To indicate the plasmonic enhancement, the maximum local electric field enhancement factor $\left(\mathrm{EF}_{\max }\right)$ is defined by Equation (1):

$$
\mathrm{EF}_{\max }=\left(E_{\max } / E_{0}\right)^{2}
$$

where $E_{0}$ is the amplitude of incident electric field.

Figure $1 \mathrm{~b}$ shows the $\mathrm{EF}_{\max }$ calculated for various $x$ values. Ag NPs $(x=0)$ possess much more intense $\mathrm{EF}_{\max }$ than $\mathrm{Au} \mathrm{NPs}(x=1)$, and in the alloy system, the $\mathrm{EF}_{\max }$ drastically decreases with an increase in $x$. Thus, precise control of the alloy composition would enhance the photocatalytic activity through the fulfilment of the optical requirements. Although the control of the Au-Ag alloy composition is generally difficult because of the large difference in the reduction potentials of $\mathrm{Ag}^{+}$and $\mathrm{Au}^{3+}$ ions [11], $\mathrm{Au}-\mathrm{Ag}$ alloy NPs have been synthesized by co-reduction of $\mathrm{HAuCl}_{4}$ and $\mathrm{AgNO}_{3}$ with $\mathrm{NaBH}_{4}$ [12,13], citric acid [14], starch [15] or wolfberry fruit extract [16], and by $\gamma$-ray irradiation [17]. We have recently reported a photochemical method for preparing $\mathrm{Au}-\mathrm{Ag}$ alloy NP-incorporated $\mathrm{AgBr}$ crystals on $\mathrm{TiO}_{2}\left(\mathrm{Au}-\mathrm{Ag} @ \mathrm{AgBr} / \mathrm{TiO}_{2}\right)$ [18].

In this study, a method has been developed to synthesize support-free $\mathrm{Au}-\mathrm{Ag} @ \mathrm{AgBr}$ crystals with varying alloy compositions. The characterization of the samples and FDTD calculations for the model system indicate that $\mathrm{Au}-\mathrm{Ag} @ \mathrm{AgBr}$ crystals are a promising material for plasmonic photocatalysis.

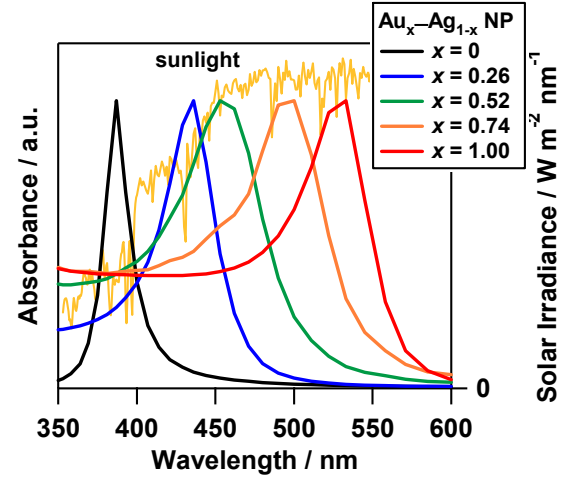

(a)

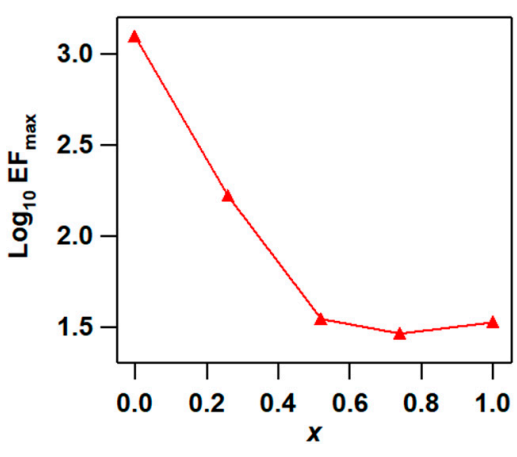

(b)

Figure 1. (a) Finite-difference time-domain (FDTD)-calculated absorption spectra of $A u_{x}-A_{1-x}$ alloy nanoparticles ( $x$, mole fraction of $\mathrm{Au}$ ) with a diameter of $5 \mathrm{~nm}$ in water. The absorption intensity is normalized with respect to the peak. (b) Maximum local electric field enhancement factor $\left(\mathrm{EF}_{\max }\right)$ as a function of $x$. This data was cited from reference [18].

\section{Results and Discussion}

\subsection{Synthesis of $A u-A g @ A g B r$}

The $\mathrm{Cl}^{-}$ligands of $\mathrm{HAuCl}_{4}$ were substituted to $\mathrm{Br}^{-}$ligands by the addition of $\mathrm{KBr}$ aqueous solution. The resulting $\mathrm{HAuBr}_{4}$ is further reduced to $\mathrm{HAuBr}_{2}$ by water in the presence of $\mathrm{AgNO}_{3}$ (Equation (2)) [18] due to the negative standard Gibbs energy of the reaction $\left(\Delta_{\mathrm{r}} G_{0}=-57.6 \mathrm{~kJ} \mathrm{~mol}^{-1}\right)$.

$$
\mathrm{AuBr}_{4}{ }^{-}+2 \mathrm{Ag}^{+}+\mathrm{H}_{2} \mathrm{O} \rightarrow \mathrm{AuBr}_{2}{ }^{-}+2 \mathrm{AgBr}+2 \mathrm{H}^{+}+1 / 2 \mathrm{O}_{2},
$$

Then, the slow addition of $\mathrm{AgNO}_{3}$ aqueous solution to $\mathrm{KBr}$ aqueous solution containing $\mathrm{HAuBr}_{4}$ at varying concentrations $\left(C_{\text {sol }}\right)$ yields $\mathrm{Au}^{+}$ion-doped $\mathrm{AgBr}$ particles $\left(\mathrm{AgBr}: \mathrm{Au}^{+}\right)$. The mole percent of $\mathrm{Au}$ to $\mathrm{Ag}$ in $\mathrm{AgBr}: \mathrm{Au}^{+}(y=((\mathrm{Au}$ mole/Ag mole $) \times 100))$ was determined by inductively coupled plasma spectroscopy. Figure 2a shows the relationship between $y$ and $C_{\text {sol }}$. The $y$ value monotonically increases with an increase in $C_{\text {sol }}$, and thus the Au-doping amount can be precisely controlled by the Au-complex concentration. X-ray diffraction (XRD) measurements were carried out for $\mathrm{AgBr}: \mathrm{Au}^{+}$with varying $\mathrm{Au}^{+}$ion-doping amounts. As shown in Figure $2 \mathrm{~b}$, diffraction peaks at $2 \theta=26.8^{\circ}, 31.0^{\circ}, 44.4^{\circ}$, 
$55.1^{\circ}, 64.5^{\circ}, 73.2^{\circ}$ were indexed as the diffraction from the (111), (200), (220), (222), (400), and (331) crystal planes of $\mathrm{AgBr}$, respectively, and are observed in every sample.



(a)

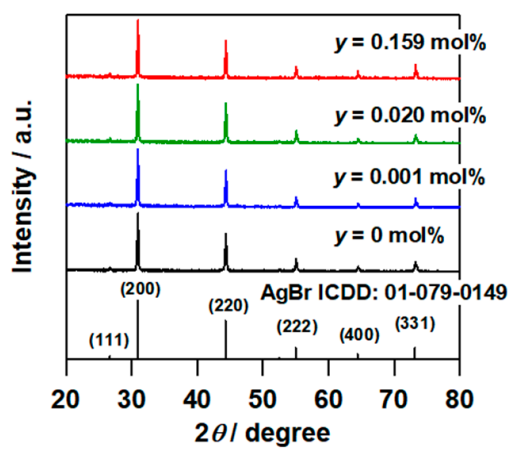

(b)

Figure 2. (a) Plots of Au doping amount $(y)$ as a function of the added $\mathrm{HAuCl}_{4}$ concentration $\left(C_{\mathrm{sol}}\right)$. (b) $\mathrm{X}$-ray diffraction $(\mathrm{XRD})$ patterns for $\mathrm{AgBr}: \mathrm{Au}^{+}$and $\mathrm{AgBr}$ reference pattern of the international center for diffraction data (ICDD).

Next, a methanol suspension of $\mathrm{AgBr}: \mathrm{Au}^{+}$was illuminated by ultraviolet light emitting diode (UV-LED) $(\lambda=365 \mathrm{~nm})$. Figure 3 a shows the scanning electron microscopy (SEM) image of the sample $(y=0.159 \mathrm{~mol} \%)$ obtained after UV-light irradiation. Micrometer-sized particles are observed, and the other samples with different Au-doping amounts had a similar size and shape. In order to directly confirm the formation of metal NPs in $\mathrm{AgBr}$, the surrounding $\mathrm{AgBr}$ was selectively dissolved by an aqueous solution of $7.5 \mathrm{M} \mathrm{NaCl}$ and $40 \mathrm{mM}$ octadecyltrimetylammonium chloride. Figure $3 \mathrm{~b}$ shows a high resolution transmission electron microscopy (HR-TEM) image for a metal NP obtained after dissolving the AgBr matrix of irradiated Au-Ag@AgBr $(y=0.041 \mathrm{~mol} \%)$. The particle size is approximately $5 \mathrm{~nm}$, and the observed $d$-spacing is in agreement with the values of $\mathrm{Au}$ (111) and $\mathrm{Ag}$ (111) planes $(\mathrm{Au}(111)=0.236 \mathrm{~nm}$ (the international center for diffraction data (ICDD) No. 00-004-0784), $\operatorname{Ag}(111)=0.237 \mathrm{~nm}($ ICDD No. 01-071-3752)). Figure 3c shows energy dispersive X-ray spectroscopy (EDX) line-elemental analysis for the metal NP. While the intensity of Au is smaller compared with that of Ag due to the small doping amount of $\mathrm{Au}(y=0.041 \mathrm{~mol} \%), \mathrm{Ag}$ and Au co-exist homogeneously in the metal NP in contrast to the core-shell structure [19]. Evidently, the Au-Ag alloy NP-incorporated $\mathrm{AgBr}$ crystals are formed by this solid-phase photochemical reaction. No change in the XRD patterns of $\mathrm{AgBr}: \mathrm{Au}^{+}$was observed before and after irradiation, most likely due to the small amounts of the metal NPs generated.

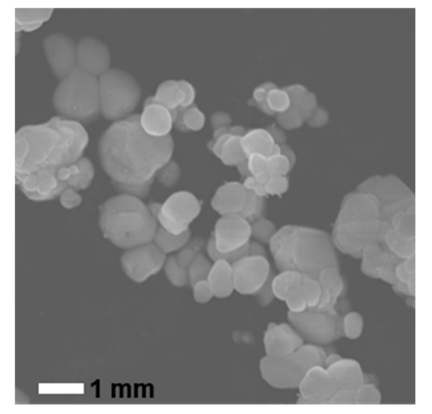

(a)

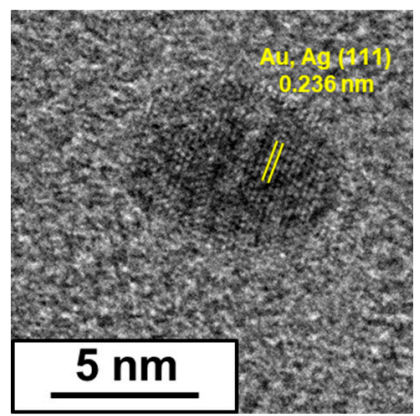

(b)

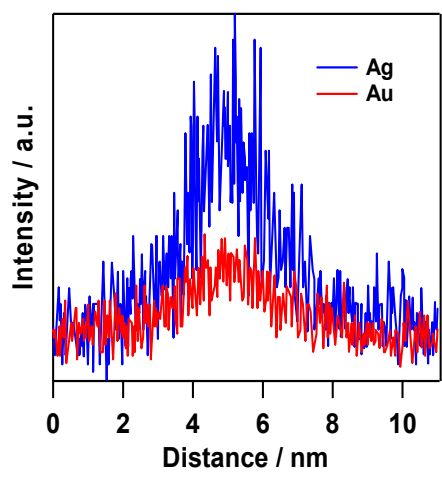

(c)

Figure 3. (a) Scanning electron microscopy (SEM) image of $\mathrm{Au}-\mathrm{Ag} @ \mathrm{AgBr}(y=0.159 \mathrm{~mol} \%)$. High resolution transmission electron microscopy (HR-TEM) image (b) and energy dispersive X-ray spectroscopy (EDX) analysis (c) of metal nanoparticles obtained from Au-Ag@AgBr ( $y=0.041 \mathrm{~mol} \%)$ by dissolving $\mathrm{AgBr}$. 


\subsection{Optical Properties of $A u-A g @ A g B r$}

Figure $4 \mathrm{a}, \mathrm{b}$ compares the UV-Vis absorption spectra of $\mathrm{AgBr}: \mathrm{Au}^{+}$with varying $y$ before (Figure $4 \mathrm{a}$ ) and after (Figure $4 \mathrm{~b}$ ) irradiation by UV-LED. Before irradiation, all samples possess strong absorption below $470 \mathrm{~nm}$ due to the interband transition of $\mathrm{AgBr}$ with a very weak LSPR absorption. After irradiation, the LSPR greatly intensifies around 500-600 nm, which also indicates the growth of Ag and/or Au NPs in AgBr by irradiation.

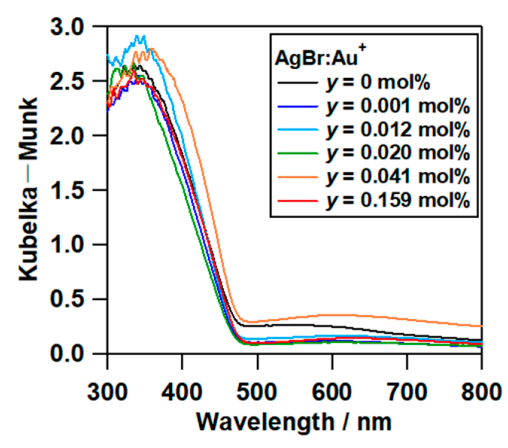

(a)



(b)

Figure 4. (a) UV-visible absorption spectra for $\mathrm{AgBr}: \mathrm{Au}^{+}$with varying $y$ before (a) and after (b) irradiation with UV light.

Figure 5a shows the UV-Vis absorption spectra of the $\mathrm{Au}-\mathrm{Ag}$ colloids obtained by dissolving the $\mathrm{AgBr}$ matrix of Au-Ag@AgBr. At $y=0$, the LSPR peak is located at $414 \mathrm{~nm}$, and the increase in $y$ causes the redshift in the LSPR peak and its significant broadening. A similar trend was observed for the $\mathrm{Au}-\mathrm{Ag}$ colloids obtained from $\mathrm{Au}-\mathrm{Ag} @ \mathrm{AgBr} /$ mesoporous- $-\mathrm{TiO}_{2}$ in the previous report, although the alloy composition could not be determined [18]. Figure $5 b$ shows the LSPR peak position $\left(\lambda_{\max }\right)$ for the $\mathrm{Au}-\mathrm{Ag}$ colloids as a function of $y$. In each case, the $\lambda_{\max }$ monotonically increases with an increase in $y$. Thus, Au-Ag alloy NP-incorporated AgBr crystals can be formed by the solid-phase photochemical reaction, and the alloy composition can be simply controlled by the Au doping amount.

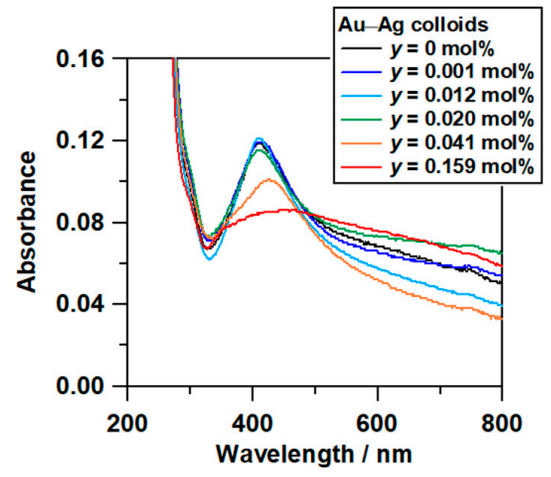

(a)

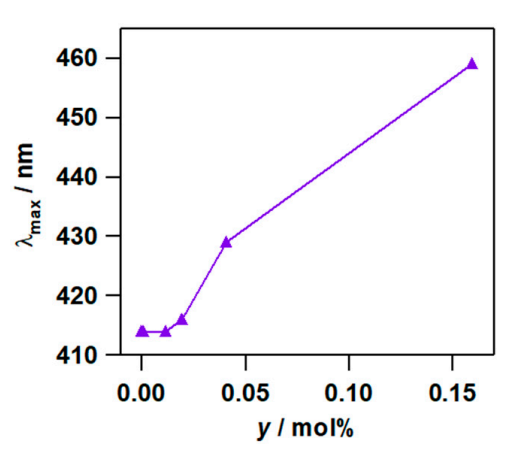

(b)

Figure 5. (a) UV-visible absorption spectra for $\mathrm{Au}-\mathrm{Ag}$ aqueous colloids prepared from $\mathrm{Au}-\mathrm{Ag} @ \mathrm{AgBr}$ by dissolving AgBr. (b) Plots of $\lambda_{\max }$ of localized surface plasmon resonance (LSPR) as a function of Au-doping amount (y).

\subsection{Mechanism on the Formation of $A u-A g @ A g B r$}

We propose a reaction mechanism on the solid-state photochemical formation of $\mathrm{Au}-\mathrm{Ag}$ alloy NP-incorporated $\mathrm{AgBr}$ crystals by taking the results of the previous density functional theory calculations [18] (Scheme 1). The $\mathrm{Au}^{+}$ions doped into $\mathrm{AgBr}$ substitute the interstitial $\mathrm{Ag}$ ions $\left(\mathrm{Ag}_{\mathrm{i}}^{+}\right)$to occupy the interstitial sites $\left(\mathrm{Au}_{\mathrm{i}}^{+}\right)$. The rise in $C_{\text {sol }}$ increases the mole ratio of the $\mathrm{Au}_{\mathrm{i}}{ }^{+}$ ions $(m)$ to $\mathrm{Ag}_{\mathrm{i}}{ }^{+}$ions $(n)$. Irradiation of $\mathrm{AgBr}$ by photons with more energy $(h v)$ than the band gap 
excites the electrons from the valence band (VB) to the conduction band (CB) (Equation (3)). Methanol works as a sacrificial electron donor for the VB-holes $\left(\mathrm{h}^{+} \mathrm{VB}\right.$ ) (Equation (4)). On the other hand, the CB-electrons $\left(\mathrm{e}^{-} \mathrm{CB}\right)$ can be trapped by the levels of the interstitial ions $\mathrm{Ag}_{\mathrm{i}}{ }^{+}$or $\mathrm{Au}_{\mathrm{i}}{ }^{+}\left(\mathrm{M}_{\mathrm{i}}^{+}\right)$(Equation (5)). Due to the large electronegativity, the resulting metal atom $(\mathrm{M})$ collects $\mathrm{e}^{-}{ }_{\mathrm{CB}}$ to generate a metal anion (Equation (6)) [20]. $\mathrm{Ag}^{+}$ions can easily migrate in an $\mathrm{AgBr}$ lattice with a low activation energy $\left(\sim 4 \mathrm{~kJ} \mathrm{~mol}^{-1}\right)$ [21]. Thus, the $\mathrm{Ag}_{\mathrm{i}}{ }^{+}$and $\mathrm{Au}_{\mathrm{i}}{ }^{+}$ions can migrate to the $\mathrm{Ag}$ and $\mathrm{Au}$ metal anions to generate a diatomic metal cluster (Equation (7)). Through repetition of these processes, $\mathrm{Au}_{x}-\mathrm{Ag}_{1-x}$ alloy NPs grow in $\mathrm{AgBr}$ crystals, and the mole ratio of $\mathrm{Au}(x=m /(m+n))$ can be changed by $C_{\text {sol }}$ or the amount of doped $\mathrm{Au}^{+}$ions (y) (Equation (8)).

$$
\begin{gathered}
\mathrm{AgBr}+h v \rightarrow \mathrm{e}^{-} \mathrm{CB}+\mathrm{h}^{+}{ }_{\mathrm{VB}}, \\
\mathrm{h}^{+}{ }_{\mathrm{VB}}+\mathrm{CH}_{3} \mathrm{OH} \rightarrow \mathrm{OP},
\end{gathered}
$$

where OP denotes the oxidized product.

$$
\mathrm{M}_{\mathrm{i}}^{+}+\mathrm{e}^{-} \mathrm{CB} \rightarrow \mathrm{M},
$$

where the $\mathrm{Au}$ or $\mathrm{Ag}$ metal atom is abbreviated as $\mathrm{M}$.

$$
\begin{aligned}
\mathrm{M}+\mathrm{e}^{-} \mathrm{CB} & \rightarrow \mathrm{M}^{-}, \\
\mathrm{M}^{-}+\mathrm{M}_{\mathrm{i}}^{+} & \rightarrow \mathrm{M}^{-} \mathrm{M}, \\
\mathrm{M}-\mathrm{M}+\mathrm{M}_{\mathrm{i}}^{+}+\mathrm{e}^{-}{ }_{\mathrm{CB}} & \rightarrow \cdots \rightarrow \mathrm{Au}_{\mathrm{m}}-\mathrm{Ag}_{\mathrm{n}},
\end{aligned}
$$

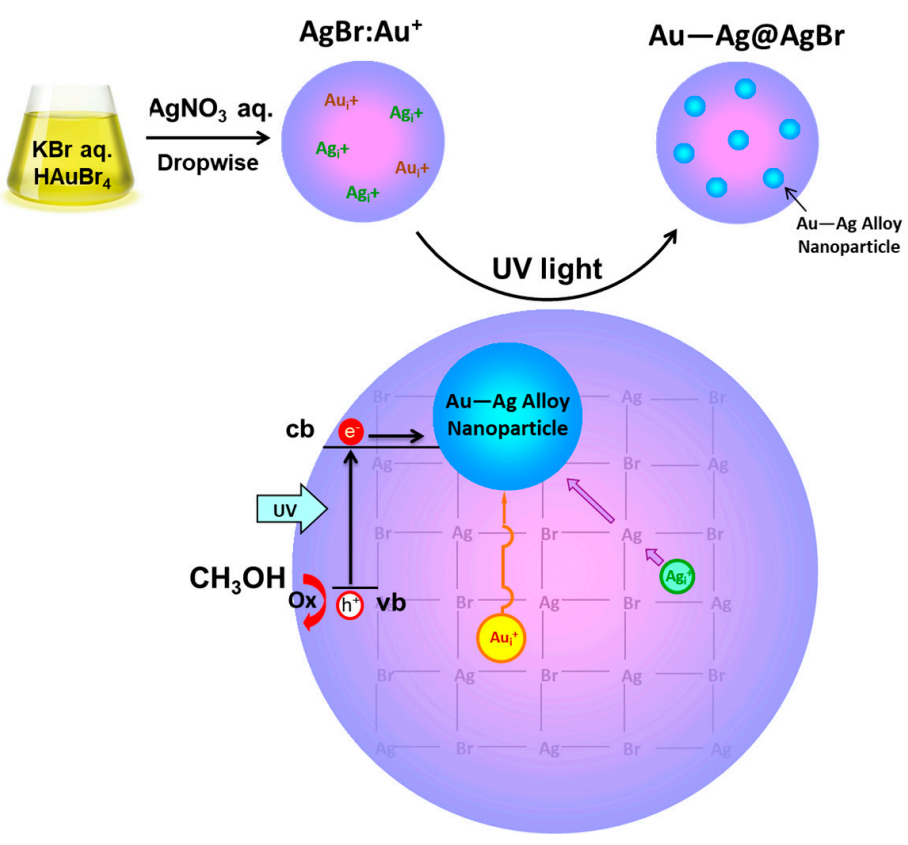

Scheme 1. Proposed mechanism for the synthesis of Au-Ag alloy nanoparticle-incorporated AgBr crystals.

\section{Experimental Section}

\subsection{Catalyst Preparation and Characterization}

An aqueous solution of $\mathrm{KBr}(0.1 \mathrm{M}, 80 \mathrm{~mL})$ containing $\mathrm{HAuBr}_{4}(0-1 \mathrm{mM})$ was prepared by dissolution of $\mathrm{HAuCl}_{4}$ and $\mathrm{KBr}$ in distilled water. $\mathrm{AgNO}_{3}$ aqueous solution $(0.1 \mathrm{M}, 40 \mathrm{~mL})$ was added dropwise slowly to the solution at $0.5 \mathrm{~mL} \mathrm{~min}^{-1}$ using a Perista pump. The resulting suspension was 
stirred at room temperature for $1 \mathrm{~h}$. The particles collected by centrifugation were washed with distilled water three times and dried in vacuo to obtain $\mathrm{AgBr}: \mathrm{Au}^{+}$. The amounts of $\mathrm{Ag}$ and $\mathrm{Au}$ in the reaction solutions before and after the formation of $\mathrm{AgBr}$ particles were determined by inductively coupled plasma spectroscopy (ICPS-7000, Shimadzu). From the difference in each amount, the mole numbers of $\mathrm{Ag}$ and $\mathrm{Au}$ contained in $\mathrm{AgBr}: \mathrm{Au}^{+}$were calculated. The particles $(100 \mathrm{mg})$ were re-dispersed into methanol $(20 \mathrm{~mL})$, and illuminated by UV-light $(\lambda=365 \mathrm{~nm}$, the light intensity integrated from 310 to $\left.420 \mathrm{~nm}\left(I_{310-420}\right)=4.0 \mathrm{mWcm}^{-2}\right)$ at room temperature for $15 \mathrm{~min}$. The particles collected by centrifugation were washed with distilled water three times and dried in vacuo to obtain $\mathrm{Au}-\mathrm{Ag} @ \mathrm{AgBr}$. The sample morphology was characterized by scanning electron microscopy (SEM, Hitachi S-800) at an acceleration voltage of $10 \mathrm{kV}$. Further, the samples were observed by transmission electron microscopy (TEM) at an applied voltage of $200 \mathrm{kV}$ (JEM-2100F, JEOL). X-ray diffraction (XRD) was measured by a Mini Flex X-ray diffractometer (Rigaku) operating at $40 \mathrm{kV}$ and $100 \mathrm{~mA}$. The scans were collected in the range from $20^{\circ}$ to $90^{\circ}(2 \theta)$ by the use of $\mathrm{Cu} \mathrm{K} \alpha$ radiation $(\lambda=1.545 \AA)$. Diffuse reflectance UV-Vis-NIR spectra of the samples were recorded on a UV-2600 spectrometer (Shimadzu) with an integrating sphere unit (Shimadzu, ISR-2600Plus) by using a quartz cell at room temperature. The reflectance $\left(R_{\infty}\right)$ was recorded with respect to a reference of $\mathrm{BaSO}_{4}$, and the Kubelka-Munk function $\left[F\left(R_{\infty}\right)\right]$ expressing the relative absorption coefficient was calculated by the equation $F\left(R_{\infty}\right)=\left(1-R_{\infty}\right)^{2} / 2 R_{\infty}$.

\subsection{FDTD Calculaitons}

According to the method previously reported [17], the local electric field of $\mathrm{Au}_{x}-\mathrm{Ag}_{1-x}$ alloy NPs was analyzed by the three-dimensional (3D) finite-difference time-domain (FDTD) method using FDTD Solutions (Lumerical Solutions, Inc. Vancouver, BC, Canada). For the models constructed by fixing the metal particle size at $5 \mathrm{~nm}$, the calculations were performed in a water medium using the optical constants (refractive index and extinction coefficient) previously reported [22].

\section{Conclusions}

The optical property and local electric field enhancement of Au-Ag alloy NPs strongly depends on the alloy composition. This study has presented a photochemical method for synthesizing support-free $\mathrm{Au}-\mathrm{Ag}$ alloy NP-incorporeated AgBr crystals (Au-Ag@AgBr) with the alloy composition controlled. We anticipate that the present $\mathrm{Au}-\mathrm{Ag} @ \mathrm{AgBr}$ can be a promising plasmonic photocatalyst for efficient solar-to-chemical transformations through fine-tuning of the alloy composition.

Author Contributions: S.N. prepared the catalysts, and conducted characterization. M.F. performed FDTD calculation. H.T. supervised the experimental work and data analysis.

Funding: This research was funded by JSPS KAKENHI a Grant-in-Aid for Scientific Research (C), Grant Numbers 15K05654 and 18K05280, by the Futaba Foundation, and by the MEXT Supported Program for the Strategic Research Foundation at Private Universities.

Acknowledgments: This work was partially supported by JSPS KAKENHI a Grant-in-Aid for Scientific Research (C), Grant Numbers 15K05654 and 18K05280, by the Futaba Foundation, and by the MEXT Supported Program for the Strategic Research Foundation at Private Universities.

Conflicts of Interest: The authors declare no conflict of interest.

\section{References}

1. Panayotov, D.A.; Morris, J.R. Surface chemistry of $\mathrm{Au} / \mathrm{TiO}_{2}$ : Thermally and photolytically activated reactions. Surf. Sci. Rep. 2016, 71, 77-271. [CrossRef]

2. Tada, H. Size, shape and interface control in gold nanoparticle-based plasmonic photocatalysts for solar-to-chemical transformations. Dalton Trans. 2019, 48, 6308-6313. [CrossRef] [PubMed]

3. Kakuta, N.; Goto, N.; Ohkita, H.; Mizushima, T. Silver Bromide as a Photocatalyst for Hydrogen Generation from $\mathrm{CH}_{3} \mathrm{OH} / \mathrm{H}_{2} \mathrm{O}$ Solution. J. Phys. Chem. B 1999, 103, 5917-5919. [CrossRef]

4. An, C.; Wang, J.; Wang, S.; Zhang, Q.-H. Plasmonic enhancement of photocatalysis over Ag incorporated AgI hollow nanostructures. RSC Adv. 2014, 4, 2409-2413. [CrossRef] 
5. $\quad$ An, C.; Wang, J.; Qin, C.; Jiang, W.; Wang, S.; Li, Y.; Zhang, Q. Synthesis of Ag@AgBr/AgCl heterostructured nanocashews with enhanced photocatalytic performance via anion exchange. J. Mater. Chem. 2012, 22, 13153. [CrossRef]

6. Asi, M.A.; Zhu, L.; He, C.; Sharma, V.K.; Shu, D.; Li, S.; Yang, J.; Xiong, Y. Visible-light-harvesting reduction of CO2 to chemical fuels with plasmonic Ag@AgBr/CNT nanocom-posites. Catal. Today 2013, 216, 268-275. [CrossRef]

7. Marszewski, M.; Cao, S.; Yu, J.; Jaroniec, M. Semiconductor-based photocatalytic $\mathrm{CO}_{2}$ conversion. Mater. Horiz. 2015, 2, 261-278. [CrossRef]

8. Hayashido, Y.; Naya, S.-I.; Tada, H. Local Electric Field-Enhanced Plasmonic Photocatalyst: Formation of Ag Cluster-Incorporated AgBr Nanoparticles on $\mathrm{TiO}_{2}$. J. Phys. Chem. C 2016, 120, 19663-19669. [CrossRef]

9. Tada, H.; Naya, S.-I.; Fujishima, M. Water splitting by plasmonic photocatalysts with a gold nanoparticle/cadmium sulfide heteroepitaxial junction: A mini review. Electrochem. Commun. 2018, 97, 22-26. [CrossRef]

10. Atkins, P.; de Paula, J. Physical Chemistry, 8th ed.; Oxford University Press: New York, NY, USA, 2006.

11. Gao, C.; Hu, Y.; Wang, M.; Chi, M.; Yin, Y. Fully Alloyed Ag/Au Nanospheres: Combining the Plasmonic Property of Ag with the Stability of Au. J. Am. Chem. Soc. 2014, 136, 7474-7479. [CrossRef] [PubMed]

12. Hostetler, M.J.; Zhong, C.-J.; Yen, B.K.H.; Anderegg, J.; Gross, S.M.; Evans, N.D.; Porter, M.; Murray, R.W. Stable, Monolayer-Protected Metal Alloy Clusters. J. Am. Chem. Soc. 1998, 120, 9396-9397. [CrossRef]

13. Zielińska-Jurek, A.; Kowalska, E.; Sobczak, J.W.; Lisowski, W.; Ohtani, B.; Zaleska, A. Preparation and characterization of monometallic $(\mathrm{Au})$ and bimetallic $(\mathrm{Ag} / \mathrm{Au})$ modified-titania photocatalysts activated by visible light. Appl. Catal. B Environ. 2011, 101, 504-514. [CrossRef]

14. Link, S.; Wang, Z.L.; El-Sayed, M.A. Alloy Formation of Gold-Silver Nanoparticles and the Dependence of the Plasmon Absorption on Their Composition. J. Phys. Chem. B 1999, 103, 3529-3533. [CrossRef]

15. Sun, L.; Lv, P.; Li, H.; Wang, F.; Su, W.; Zhang, L. One-step synthesis of Au-Ag alloy nanoparticles using soluble starch and their photocatalytic performance for 4-nitrophenol degradation. J. Mater. Sci. 2018, 53, 15895-15906. [CrossRef]

16. Sun, L.; Yin, Y.; Lv, P.; Su, W.; Zhang, L. Green controllable synthesis of Au-Ag alloy nanoparticles using Chinese wolfberry fruit extract and their tunable photocatalytic activity. RSC Adv. 2018, 8, 3964-3973. [CrossRef]

17. Ray, P.; Clément, M.; Martini, C.; Abdellah, I.; Beaunier, P.; Rodriguez-Lopez, J.L.; Huc, V.; Remita, H.; Lampre, I. Stabilisation of small mono- and bimetallic gold-silver nanoparticles using calix [8] arene derivatives. New J. Chem. 2018, 42, 14128-14137. [CrossRef]

18. Naya, S.-I.; Hayashido, Y.; Akashi, R.; Kitazono, K.; Soejima, T.; Fujishima, M.; Kobayashi, H.; Tada, H. Solid-Phase Photochemical Growth of Composition-Variable Au-Ag Alloy Nanoparticles in AgBr Crystal. J. Phys. Chem. C 2017, 121, 20763-20768. [CrossRef]

19. Negishi, R.; Naya, S.-I.; Kobayashi, H.; Tada, H. Gold(Core)-Lead(Shell) Nanoparticle-Loaded Titanium(IV) Oxide Prepared by Underpotential Photodeposition: Plasmonic Water Oxidation. Angew. Chem. Int. Ed. 2017, 56, 10347-10351. [CrossRef] [PubMed]

20. Tada, H.; Kiyonaga, T.; Naya, S.-I. Rational design and applications of highly efficient reaction systems photocatalyzed by noble metal nanoparticle-loaded titanium(iv) dioxide. Chem. Soc. Rev. 2009, 38, 1849. [CrossRef] [PubMed]

21. Tani, T. Silver Nanoparticles from Silver Halide Photography to Plasmonics; Oxford University Press: New York, NY, USA, 2015.

22. Rodríguez, O.P.; Caro, M.; Rivera, A.; Olivares, J.; Perlado, J.M.; Caro, A. Optical properties of Au-Ag alloys: An ellipsometric study. Opt. Mater. Express 2014, 4, 403. [CrossRef]

(C) 2019 by the authors. Licensee MDPI, Basel, Switzerland. This article is an open access article distributed under the terms and conditions of the Creative Commons Attribution (CC BY) license (http://creativecommons.org/licenses/by/4.0/). 